\title{
Role of Omega-3 Unsaturated Fatty Acids in the Postpartum Depression: Systematic Review and Narrative Synthesis
}

\author{
Fatima Mougharbel ${ }^{1} \&$ Raywat Deonandan $^{1}$ \\ ${ }^{1}$ School of Interdisciplinary Health Sciences, University of Ottawa, Ottawa, Canada \\ Correspondence: Fatima Mougharbel, 37 Rue de Moscou, Gatineau, J9J 1W8, Canada. Tel: 1-613-698-5255. \\ E-mail: fmoug087@uottawa.ca
}

Received: April 11, 2016 Accepted: June 21, 2016 Online Published: July 29, 2016

doi:10.5539/gjhs.v9n3p304 URL: http://dx.doi.org/10.5539/gjhs.v9n3p304

\begin{abstract}
Background: Postpartum depression (PPD) is a complex mental health disorder that affects women during their childbearing years. It is a serious medical condition that occurs in approximately $15 \%$ of women after birth and has an adverse effect on both the mother and the infant. Hypotheses exist relating dietary deficiencies in a pregnant or postnatal woman's diet may cause postnatal depression. It is unclear whether Omega-3 polyunsaturated fatty acids (n-3 PUFAs) are effective for treating or preventing PPD.
\end{abstract}

Objectives: To assess the best available evidence to date regarding the effect of n-3 PUFAs on the etiology, prevention and treatment of postnatal depression.

Methods: A systematic review and narrative synthesis was conducted in order to address the gaps in knowledge. For the systematic review, a broad search of electronic databases of published quantitative literature was conducted. The narrative synthesis consists of four elements: 1) developing a theory; 2) developing a preliminary synthesis; 3 ) exploring relationships in the data; 4) assessing the robustness of the synthesis. Published experimental and observational studies were accepted involving women who were pregnant or who had given birth in the previous six weeks. N-3 PUFAs was the intervention of interest and PPD was the outcome.

Results: Out of 181 potential articles, a total of 17 studies met the inclusion criteria. The overwhelming majority of the studies found that n-3 PUFAs had no inverse association with PPD evaluations. Significant heterogeneity was observed among included studies.

Conclusions: Overall, This systematic review and narrative synthesis failed to find a significant positive association between n-3 PUFAs intake and PPD.

Keywords: maternal mental health, maternal nutrition, narrative synthesis, omega-3 polyunsaturated fatty acids, postpartum depression, systematic review

\section{Introduction}

Depression is a major cause of disability for all ages and both genders (World Health Organization [WHO], 2008). Women are at the highest risk of depression during their childbearing years; and the birth of a child may precipitate a depressive episode in vulnerable women (Stewart, Robertson, Dennis, Grace, \& Wallington, 2003). Postpartum depression (PPD) can affect up to $15 \%$ of new mothers during the first year after delivery (Stewart et al., 2003).

In addition to its effects on the mother, untreated PPD negatively affects the social, emotional and cognitive development of the infant (Fisher et al., 2009; Harpham et al., 2005; Logsdon, Wisner, \& Pinto-Foltz, 2006). Indeed, in severe cases, it can even lead to maternal suicide or infanticide (Fisher et al., 2009; Harpham et al., 2005).

Although antidepressants may be effective for treating PPD, many women may not want to risk taking drugs that may harm their fetuses or, for breastfeeding mothers, their newborns (Borja-Hart \& Marino, 2010; U. S. Food and Drug Administration [FDA], 2014). Taking antidepressants in the third trimester has been associated with several adverse effects, such as transient neonatal withdrawal syndrome, muscle weakness, and respiratory problems (Oberlander et al., 2004).

Thus, it is important to explore the efficacy of alternative, perhaps non-pharmaceutical or nutritional, options for PPD treatment. One such alternative worthy of exploration is supplementation with omega-3 polyunsaturated fatty 
acids (n-3 PUFAs).

N-3 PUFAs are necessary for a healthy brain function and structure; they prevent or decrease the inflammatory status occurring during depression and may be important for maintaining healthy mood and controlling mental distress (Bourre et al., 1991; Maes \& Smith, 1998; Suarez et al., 2003).

There is evidence to suggest that n-3 PUFAs decrease by $50 \%$ during gestation and may not be fully replenished up to 26 weeks postpartum (Al, Van Houwelingen, Kester et al., 1995; Al Van Houwelingen, \& Hornstra, 1997; Huang et al., 2013; Holman et al., 1991; Markhus et al., 2015; Otto et al., 1997; Van den Ham et al., 2001). Therefore, mothers may be at a risk of suffering PPD when they become depleted of n-3 PUFAs (Al, Van Houwelingen, Kester et al., 1995; Al Van Houwelingen, \& Hornstra, 1997; Hibbeln \& Salem, 1995; Huang et al., 2013; Holman et al., 1991; Otto et al., 1997; Van den Ham et al., 2001).

Several experimental and observational studies evaluated the effectiveness of the n-3 PUFAs on PPD, but there was no current systematic review that has examined all quantitative designs that have been conducted to assess the efficacy n-3 for PPD. There were, however, some brief, non-systematic literature and article reviews which dealt with a broad range of issues related to our topic rather than addressing the n-3 PUFAs and PPD in particular in depth (Borja-Hart \& Marino, 2010; Freeman, 2006; Levant, 2010; Jans, Giltay, \& Willem Van der Does, 2010; Ramakrishnan, 2011; Wojcicki \& Heyman, 2011).

Research indicated that systematic reviews are more transparent than literature and article reviews with a goal of decreasing bias by identifying, appraising, and synthesizing all relevant studies on a specific topic (Uman, 2001).

As no systematic review was conducted on the role of n-3 PUFAs for PPD, the aim of this study was to fill this gap of knowledge and update the current information about the overall published evidence concerning whether $n-3$ PUFAs exposure in the perinatal and postpartum period are beneficial for treating depression, up to 12 months post-partum.

\section{Methods}

We employed a systematic review of published evidence, with a narrative synthesis in lieu of statistical meta-analysis (Cochrane Collaboration, 2008; Popay et al., 2006).

\subsection{Searching the Literature}

With the assistance of a librarian, research papers published in English between 1990 and 2014 were identified via searches of the following databases: Ovid, CINHAL (Cumulative Index of Nursing and Allied Health Literature), Embase, Chochrane, and Google Scholar, using the following keywords, their derivatives and conjugated terms: "fish oils", OR "omega fatty acids", OR "omega-3", OR "fatty acids", OR " $\alpha$ linolenic acid", OR “docosahexaenoic acids", OR "eicosapentaenoic acid" AND "Postpartum depression", OR "postnatal depression".

Abstracts, animal studies, and individual case reports were excluded, as were studies that failed to clearly describe the intervention and outcome measures.

\subsection{Quality Appraisal}

The Quality Assessment Tool for Quantitative Studies developed by the Effective Public Health Practice Project (EPHPP) was used to assess methodological quality (EPHPP, 2009; Thomas, Ciliska, Dobbins, \& Micucci, 2004). This quality assessment tool allows quantitative studies (randomized and nonrandomized trials) to be rated on six components: selection bias, study design, confounders, blinding, data collection methods, withdrawals and dropouts. Each study was rated as "strong," "moderate," or "weak" on each of these components. An overall global rating was then given to each study with studies classified as "strong" (at least four strong ratings without any weak ratings), "moderate" (less than four strong ratings and one weak rating), or "weak" (two or more weak ratings).

Concerning the data collection methods, the validity and reliability of the methods were rated in relation to PPD outcome measures only.

\subsection{Data Abstraction}

The following data were abstracted: study designs, characteristics of the participants and interventions, intervention measurement, outcome measurement, findings and limitations.

\subsection{Data Synthesis}

A narrative synthesis of the findings about the association between n-3 PUFAs intake and PPD was carried out. This stepwise narrative methodology has been used previously in a wide range of study reviews (Arai et al., 2007; Dennison et al., 2009). 
Narrative synthesis is an approach to synthesis findings that relies mainly on the use of words and text to summarize and explain findings. It is typically used when statistical meta-analysis is not suitable. Due to the significant clinical variability (variability in the participants, interventions and outcomes studied also variability in outcome measures) and methodological heterogeneity (variability in study design) between the selected studies of the papers in this study, statistical meta-analysis was contra-indicated, hence our reliance upon narrative methods. The four stages of the narrative synthesis were: (i) developing a theory; (ii) developing a preliminary synthesis; (iii) exploring relationships within and between studies; and (iv) assessing the robustness of the synthesis.

\subsubsection{Element 1: Developing a Theory}

This part is concerned with "how the intervention works, why, and for whom" (Popay et al., 2006, p.12).The purpose of this part is to develop an understanding of the theory behind the intervention in order to inform decisions about the review question and the types of studies to include. It is also important in "contributing to the interpretation of the review's findings and will be valuable in assessing how widely applicable those findings may be" (Popay et al., 2006, p.12).

\subsubsection{Element 2: Developing a Preliminary Synthesis}

The preliminary synthesis provides a description of the results of all included research studies in order to organize findings to provide an initial description of patterns across included studies (Popay et al., 2006). Studies were organized according to design and effects. For each included paper, the following data were extracted and tabulated: type of paper, study location, methodological approach, participant information and inclusion criteria, intervention and outcomes measurement, summary of main study findings, and limitation.

\subsubsection{Element 3: Exploring Relationships Within and Between Studies}

The purpose of this element is to consider relationship: first between study results and Key aspects for other studies and second the factors across included studies (Popay et al., 2006). The outcomes that emerged from the preliminary synthesis were subjected to further rigorous evaluation to identify any factors that may explain the differences within and across the included studies and to understand how and why n-3 PUFAs have or do not have an effect on PPD.

\subsubsection{Element 4: Assessing the Robustness of the Synthesis}

Assessing methodological quality is a way to ensure the robustness of the synthesis. The analysis of relationships within and between studies described previously helps in creating a thorough assessment of the strength of the evidence available for drawing conclusions on the basis of a narrative synthesis (Popay et al., 2006).

\section{Overall Results in Context with Expectations Arising from the Literature (Narrative Synthesis Element 2: Developing a Preliminary Synthesis)}

Our search produced 181 studies, though only 17 met our criteria: eight experimental and nine observational studies. Of the former, six were randomized controlled trials (Doornbos et al., 2009; Freeman et al., 2008; Llorent et al., 2003; Makrides et al., 2010; Mozurkewich et al., 2013; Rees, Austin, \& Parker, 2008) and two pilot trials (Freeman et al., 2006; Marangell et al., 2004). The nine observational studies included: one ecological study (Hibbeln, 2002), a cross-sectional study (De Vriese, Christophe, \& Maes, 2003), a case-control study (Browne, Scott, \& Silvers, 2006), and six cohort studies (da Rocha \& Kac, 2012; Markhus et al., 2013; Miyake et al., 2006; Otto, De Groot, \& Hornstra, 2003; Parker et al., 2014; Strøm, Mortensen, Halldorsson, Thorsdottir, \& Olsen, 2009). The included studies and the results of our quality appraisals are summarized in Table A1, while more detail on the characteristics of the studies is presented in Table A2.

Excluded studies were: review and journal articles $(\mathrm{N}=113)$; editorials $(\mathrm{N}=9)$; animal studies $(\mathrm{N}=6)$; duplicate studies $(\mathrm{N}=5)$; abstracts only $(\mathrm{N}=2)$; different interventions and outcomes $(\mathrm{N}=28)$, lack of sufficient data $(\mathrm{N}=1)$.

In terms of methodological quality assessment, our set indicated five strong, nine moderate, and three weak studies. Weak rating scores were given because of a poor study design, lack of controlling confounders, and/or high dropout rates. The most common reasons for a study not receiving a 'strong' rating were a low response rate from eligible participants and high withdrawal/dropout rate.

Significant heterogeneity was observed among included studies, hence justifying our narrative synthesis approach. There are large differences among them in terms of study designs, sample size, population and time period of the study (depressed or healthy participants, pregnant and/or postpartum), characteristics of the intervention in terms of (type, dosage, duration), and choice of measures of predictors and outcomes. 


\section{Discussion (Narrative Synthesis: Element 3)}

We demonstrated that the results of the use omega-3 PUFA as therapeutic and preventative agents for postpartum depression were varied. Many limitations complicated the interpretation of the findings, most prominently the small sample size, as only 17 studies met the inclusion criteria.

Furthermore, clinical and methodological heterogeneity were high. It was noticeable that the heterogeneity between studies may depend on clinical and methodological issues. Intervention trials were varied in terms of characteristics and number of participants, depression scales employed (EPDS, HAM-D, or BDI), baseline depression score, the nature of the intervention (e.g., formulation, dose, duration, timing, etc.), time period of study and supplementation (i.e., antenatal, postnatal or combined antenatal/postnatal), lack of control group, open label trials, low supplement dosages, under-reporting of fatty acid intake, short-term follow-up, unsuitable ratios of EPA:DHA. This considerable variability made the discussion of results more complex.

In addition, most studies measured depression using the EPDS without verification of high EPDS scores with a clinical diagnosis of depression, which can result in biased results since a high EPDS score can be due to anxiety as well as from depression (Stuart, Couser, Schilder, O'hara, \& Gorman, 1998).

Moreover, information regarding the pathophysiological nature of depression occurring in patients was lacking. Indeed, none of the studies reviewed evaluated the brain or synaptic DHA levels, while few assessed DHA levels in the plasma (Browne et al., 2006; De Vriese et al., 2003; Doornbos et al., 2009; Makrides et al., 2010; Markhus et al., 2013; Llorent et al., 2003; Mozurkewich et al., 2013; Parker et al., 2014; Rees et al., 2008).

Research showed that regional levels of brain DHA metabolism can be measured in human with Positron Emission Tomography (PET) and following intravenous injection of [1-11C] DHA (Rapoport, Ramadan, \& Basselin, 2011; Rapoport, 2013).

It has been hypothesized that $n-3$ PUFAs affects synaptic function by impacting membrane structure and through cytokine-immuno neuroendocrine interactions (Maes et al., 1998). Other studies stated that plasma levels of fatty acids are not a perfect measure of dietary intake nor a perfect predictor of fatty acid levels in brain tissue (Rapoport, Ramadan, \& Basselin, 2011; Shapiro et al., 2012). While Erythrocytes are considered the gold standard to measure the long-term n-3PUFA status, However, several studies have indicated strong correlations between FA content of erythrocytes and plasma; consequently, we can consider the plasma as a valid biomarker to reflect n-3 status over the last month (Harris, 2008; Garneau et al., 2012; Paradis, Pérusse, Godin, \& Vohl, 2008) Such theories could explain the lack of association found in some of the studies reviewed here between n-3 PUFAs supplementation and prevention of PPD.

Lastly, some important issues concerning the delivery of the intervention have been explored in recent meta-analyses, which showed that the positive effects of n-3 PUFAs on depressive symptoms appeared to depend more on EPA administration rather than DHA, severity of depression, and study quality (Bloch \& Hannestad, 2012). However, some concerns regarding these findings still persist (Lin et al., 2012). The findings regarding the different efficacy of EPA compared to DHA and EPA-DHA combinations were confirmed by Grosso et al., (2014) in a meta-analysis in which the researchers grouped RCT's based on the type of n-3 PUFAs administered. Whether EPA is more effective than DHA, in improving depression, the different effects of the types of $n-3$ PUFAs is challenging for convincing explanation since DHA is a major structural constituent of neuronal membranes (Grosso et al., 2014). Thus, that increasing its dietery intake would be valuable on brain function, rather than EPA, which exists at lower levels (Arterburn, Hall, \& Oken, 2006; Grosso et al., 2014).

Although heterogeneity among included studies makes it difficult to synthesize the findings, our narrative approach indicates a null benefit of n-3 PUFAs on depressive symptoms postpartum, as only one small pilot trial (Freeman et al., 2006), one weak ecological study (Hibbeln, 2002), and four small cohort and cross-sectional studies (da Rocha \& Kac, 2012; De Vriese, Christophe, \& Maes, 2003; Markhus et al., 2013; Otto, De Groot, \& Hornstra, 2003) reported promising results, whilenone of the RCTs identified in this review showed an association of n-3 PUFAs with a decreased risk for maternal PPD.

In short, the only studies showing positive associations were of small sample size and comparatively weak designs.

Future research should focus on identifying the specific molecular mechanisms underlying the function of n-3 PUFAs in the brain. Moreover, factors related to the pathophysiological nature of the depression should be considered.

Our findings should not marginalize the other significant benefits of n-3 PUFAs. Many studies suggested an important role of n-3 PUFAs for fetal development including neuronal, retinal, and immune function (Dunstan et 
al., 2004; Greenberg, Bell, \& Van Ausdal, 2008; Swanson, Block, \& Mousa, 2012).

Research indicated that women during pregnancy and lactation are not getting enough n-3 PUFAs (Denomme, Stark, \& Holub, 2005; Jia et al., 2015). In June, 2014, The Food and Drug Administration (FDA) issued an updated statement advising women to eat more fish during pregnancy and breastfeeding to aid in fetal growth and development. The FDA's recommendations are consume 8 to 12 ounces of a variety of fish each week from choices that are lower in mercury during pregnancy and breastfeeding (U. S. Food and Drug Administration, 2014).

\section{Reflecting Critically on the Synthesis Process (Narrative Synthesis Element 4: Assessment of the Robustness of the Synthesis)}

This is the first narrative synthesis systematic review on n-3 PUFAs and PPD literature. The use of defined eligibility criteria, the application of a rigorous search strategy, and the quality assessment of the studies and systematic analysis of the findings made this review transparent. However, there are some limitations to the approach taken in this systematic review and narrative synthesis.

First of all, the different designs of included studies increased heterogeneity. Also, the diversity of outcomes that result from different contexts and the heterogeneous research studies limited the extent to which clear conclusions could be drawn about the usefulness of n-3 PUFAs in PPD. One systematic review and synthesis cannot overcome these complexities alone, but can provide some clarity about the research evidence and its implications for practice and further research.

In addition, since the review yielded a small sample size, it is possible that the aim of the present research may not have been adequately addressed, particularly with relation to the ability to decide whether n-3 PUFAs components are effective for PPD.

The literature search required screening in the most potential databases using a robust search strategy and undertaking empirical checks on the inclusiveness of the search strategy results. However, only studies in the English language were included. It is unknown what other relevant materials in other languages was missed due to this limitation.

Overall, the narrative synthesis methodology used in this review facilitated the understanding and acknowledgement of the broader influences of theoretical and contextual variables when it was challenging to interpret multiple forms of heterogeneous studies. This method was suitable for integrating quantitative research findings and important as a mechanism for drawing messages from research in order to draw our own recommendations for future implication.

\section{Conclusion}

The majority of the studies found that PUFA had no association with PPD. The minority that reported a beneficial effect were of poor quality. In conclusion, n-3 PUFAs cannot be considered to be an empirically supported treatment or method for the prevention of PPD. However, since there are other benefits for n-3 PUFAs, then there is no harm in including them in prenatal/postnatal care.

\section{Competing Interests Statement}

The authors declare that there is no conflict of interests regarding the publication of this paper.

\section{References}

Al, M. D., Van Houwelingen, A. C., \& Hornstra, G. (1997). Relation between birth order and the maternal and neonatal docosahexaenoic acid status. European journal of clinical nutrition, 51(8), 548-553. http://dx.doi.org/10.1038/sj.ejen.1600444

Al, M. D., Van Houwelingen, A. C., Kester, A. D., Hasaart, T. H., De Jong, A. E., \& Hornstra, G. (1995). Maternal essential fatty acid patterns during normal pregnancy and their relationship to the neonatal essential fatty acid status. British Journal of Nutrition, 74(01), 55-68. http://dx.doi.org/10.1079/BJN19950106

Arai, L., Britten, N., Popay, J., Roberts, H., Petticrew, M., Rodgers, M., \& Sowden, A. (2007). Testing methodological developments in the conduct of narrative synthesis: a demonstration review of research on the implementation of smoke alarm interventions. Evidence \& Policy: A Journal of Research, Debate and Practice, 3(3), 361-383. http://dx.doi.org/10.1332/174426407781738029

Arterburn, L. M., Hall, E. B., \& Oken, H. (2006). Distribution, interconversion, and dose response of n-3 fatty acids in humans. The American journal of clinical nutrition, 83(6), S1467-1476S.

Bloch, M. H., \& Hannestad, J. (2012) Omega-3 PUFAs for the treatment of depression: systematic review and 
meta-analysis. Mol Psychiatry, 17, 1272-1282. http://dx.doi.org/10.1038/mp.2011.100

Borja-Hart, N. L., \& Marino, J. (2010).Role of Omega-3 Fatty Acids for Prevention or Treatment of Perinatal Depression. Pharmacotherapy: The Journal of Human Pharmacology and Drug Therapy, 30(2), 210-216. http://dx.doi.org/10.1592/phco.30.2.210

Bourre, J. M., Dumont, O., Piciotti, M., Clement, M., Chaudiere, J., Bonneil, M., \& Durand, G. (1991). Essentiality of omega 3 fatty acids for brain structure and function. World review of nutrition and dietetics, 66 , 103.

Browne, J. C., Scott, K. M., \& Silvers, K. M. (2006). Fish consumption in pregnancy and omega-3 status after birth are not associated with postnatal depression. Journal of affective disorders, 90(2), 131-139. http://dx.doi.org/10.1016/j.jad.2005.10.009

da Rocha, C. M., \& Kac, G. (2012). High dietary ratio of omega-6 to omega-3 polyunsaturated acids during pregnancy and prevalence of post-partum depression. Maternal \& child nutrition, 8(1), 36-48. http://dx.doi.org/10.1111/j.1740-8709.2010.00256.x

De Vriese, S. R., Christophe, A. B., \& Maes, M. (2003). Lowered serum n-3 polyunsaturated fatty acid (PUFA) levels predict the occurrence of postpartum depression: further evidence that lowered n-PUFAs are related to major depression. Life sciences, 73(25), 3181-3187. http://dx.doi.org/10.1016/j.lfs.2003.02.001

Dennison, L., Moss-Morris, R., \& Chalder, T. (2009). A review of psychological correlates of adjustment in patients with multiple sclerosis. Clinical psychology review, 29(2), 141-153. http://dx.doi.org/10.1016/j.cpr.2008.12.001

Doornbos, B., Van Goor, S. A., Dijck-Brouwer, D. A. J., Schaafsma, A., Korf, J., \&Muskiet, F. A. J. (2009). Supplementation of a low dose of DHA or DHA+ AA does not prevent peripartum depressive symptoms in a small population based sample. Progress in Neuro-Psychopharmacology and Biological Psychiatry, 33(1), 49-52. http://dx.doi.org/10.1016/j.pnpbp.2008.10.003

Effective Public Health Practice Project. (EPHPP). (2009). Quality Assessment Tool for Quantitative Studies. Reteived June 13, 2014, from http://www.ephpp.ca/ tools.html

Fish: What Pregnant Women and Parents Should Know: Draft Updated Advice by FDA and EPA. Retrieved from http://www.fda.gov/food/foodborneillnesscontaminants/metals/ucm393070.htm last visidet June,2015

Fisher, J., Cabral de Mello, M., \& Izutsu, T. (2009). Contemporary Topics in Women's Mental Health. Singapore: Wiley-Blackwell.

Freeman, M. P., Davis, M., Sinha, P., Wisner, K. L., Hibbeln, J. R., \& Gelenberg, A. J. (2008). Omega-3 PUFAs and supportive psychotherapy for perinatal depression: a randomized placebo-controlled study. Journal of affective disorders, 110(1), 142-148. http://dx.doi.org/10.1016/j.jad.2007.12.228

Freeman, M., Hibbeln, J. R., Wisner, K. L., Brumbach, B. H., Watchman, M., \&Gelenberg, A. J. (2006).Randomized dose-ranging pilot trial of omega-3 fatty acids for postpartum depression. Acta Psychiatrica Scandinavica, 113(1), 31-35. http://dx.doi.org/10.1111/j.1600-0447.2005.00660.x

Garneau, V., Rudkowska, I., Paradis, A. M., Godin, G., Julien, P., Pérusse, L., \& Vohl, M. C. (2012). Omega-3 fatty acids status in human subjects estimated using a food frequency questionnaire and plasma phospholipids levels. Nutrition journal, 11(1), 1.

Grosso, G., Pajak, A., Marventano, S., Castellano, S., Galvano, F., Bucolo, C., ... Caraci, F. (2014b). Role of Omega-3 PUFAs in the Treatment of Depressive Disorders: A Comprehensive Meta-Analysis of Randomized Clinical Trials. PloS one, 9(5), e96905. http://dx.doi.org/10.1371/journal.pone.0096905

Harpham, T., Huttly, S., De Silva, M. J., \& Abramsky, T. (2005).Maternal mental health and child nutritional status in four developing countries. Journal of epidemiology and community health, 59(12), 1060-1064. http://dx.doi.org/10.1136/jech.2005.039180

Harris, W. S. (2008). The omega-3 index as a risk factor for coronary heart disease. The American journal of clinical nutrition, 87(6), 1997S-2002S.

Hibbeln, J. R. (2002). Seafood consumption, the DHA content of mothers' milk and prevalence rates of postpartum depression: A cross-national, ecological analysis. Journal of affective disorders, 69(1), 15-29. http://dx.doi.org/10.1016/S0165-0327(01)00374-3

Huang, H. L., Chuang, L. T., Li, H. H., Lin, C. P., \& Glew, R. H. (2013). Docosahexaenoic acid in maternal and 
neonatal plasma phospholipids and milk lipids of Taiwanese women in Kinmen: fatty acid composition of maternal blood, neonatal blood and breast milk. Lipids in health and disease, 12(1), 27. http://dx.doi.org/10.1186/1476-511X-12-27

Lin, P. Y., Mischoulon, D., Freeman, M. P., Matsuoka, Y., Hibbeln, J., et al. (2012). Are Omega-3PUFAs antidepressants or just mood-improving agents? The effect depends upon diagnosis, supplement preparation, and severity of depression. Mol Psychiatry, 17, 1161-1163; author reply 1163-1167. http://dx.doi.org/10.1038/mp.2012.111

Llorente, A. M., Jensen, C. L., Voigt, R. G., Fraley, J. K., Berretta, M. C., \& Heird, W. C. (2003). Effect of maternal docosahexaenoic acid supplementation on postpartum depression and information processing. American journal of obstetrics and gynecology, 188(5), 1348-1353. http://dx.doi.org/10.1067/mob.2003.275

Logsdon, M. C., Wisner, K. L., \& Pinto-Foltz, M. D. (2006).The impact of postpartum depression on mothering. Journal of Obstetric, Gynecologic, \& Neonatal Nursing, 35(5), 652-658. http://dx.doi.org/10.1111/j.1552-6909.2006.00087.x

Maes, M., \& Smith, R. S. (1998). Fatty acids, cytokines, and major depression. Biological psychiatry, 43(5), 313.

Marangell, L. B., Martinez, J. M., Zboyan, H. A., \& Puryear, L. J. (2004). Omega-3 fatty acids for the prevention of postpartum depression: Negative data from a preliminary, open-label pilot study. Depression and anxiety, 19(1), 20-23. http://dx.doi.org/10.1002/da.10148

Markhus, M. W., Rasinger, J. D., Malde, M. K., Frøyland, L., Skotheim, S., Braarud, H. C., ... Graff, I. E. (2015). Docosahexaenoic Acid Status in Pregnancy Determines the Maternal Docosahexaenoic Acid Status 3-, 6-and 12 Months Postpartum. Results from a Longitudinal Observational Study. PloS one, 10(9), e0136409. http://dx.doi.org/10.1371/journal.pone.0136409

Markhus, M. W., Skotheim, S., Graff, I. E., Frøyland, L., Braarud, H. C., Stormark, K. M., \& Malde, M. K. (2013). Low omega-3 index in pregnancy is a possible biological risk factor for postpartum depression. PloS one, 8(7), e67617. http://dx.doi.org/10.1371/journal.pone.0067617

Martins, J. G., Bentsen, H., \& Puri, B. K. (2012). Eicosapentaenoic acid appears to be the key Omega-3 PUFAs component associated with efficacy in major depressive disorder: A critique of Bloch and Hannestad and updated metaanalysis. Mol Psychiatry, 17: 1144-1149; Discussion 1163-1147. http://dx.doi.org/10.1038/mp.2012.25

Miyake, Y., Sasaki, S., Yokoyama, T., Tanaka, K., Ohya, Y., Fukushima, W., \& Hirota, Y. (2006). Risk of postpartum depression in relation to dietary fish and fat intake in Japan: the Osaka Maternal and Child Health Study. Psychological medicine, 36(12), 1727-1735. http://dx.doi.org/10.1017/S0033291706008701

Mozurkewich, E. L., Clinton, C. M., Chilimigras, J. L., Hamilton, S. E., Allbaugh, L. J., Berman, D. R., \& Djuric, Z. (2013). The Mothers, Omega-3, and Mental Health Study: a double-blind, randomized controlled trial. American journal of obstetrics and gynecology, 208(4), 313-e1. http://dx.doi.org/10.1016/j.ajog.2013.01.038

Oberlander, T. F., Misri, S., Fitzgerald, C. E., Kostaras, X., Rurak, D., \& Riggs, W. (2004). Pharmacologic factors associated with transient neonatal symptoms following prenatal psychotropic medication exposure. The Journal of clinical psychiatry, 65(2), 230-237. http://dx.doi.org/10.4088/JCP.v65n0214

Otto, S. J., De Groot, R. H. M., \& Hornstra, G. (2003). Increased risk of postpartum depressive symptoms is associated with slower normalization after pregnancy of the functional docosahexaenoic acid status. Prostaglandins, leukotrienes and essential fatty acids, 69(4), 237-243. http://dx.doi.org/10.1016/S0952-3278(03)00090-5

Otto, S. J., Houwelingen, A. V., Antal, M., Manninen, A., Godfrey, K., Lopez-Jaramillo, P., \& Hornstra, G. (1997). Maternal and neonatal essential fatty acid status in phospholipids: an international comparative study. European journal of clinical nutrition, 51(4), 232-242. http://dx.doi.org/10.1038/sj.ejen.1600390

Paradis, A. M., Pérusse, L., Godin, G., \& Vohl, M. C. (2008). Validity of a self-reported measure of familial history of obesity. Nutrition Journal, 7(1), 1. http://dx.doi.org/10.1186/1475-2891-7-27

Parker, G., Hegarty, B., Granville-Smith, I., Ho, J., Paterson, A., Gokiert, A., \& Hadzi-Pavlovic, D. (2014). Is essential fatty acid status in late pregnancy predictive of post-natal depression?. Acta Psychiatrica Scandinavica.

Popay, J., Roberts, H., Sowden, A., Petticrew, M., Arai, L., Rodgers, M., ... Duffy, S. (2006). Guideline on the conduct of narrative synthesis in systematic reviews. A product from the ESRC methods programme.Version, 
1.

Rapoport, S. I. (2013). Translational studies on regulation of brain docosahexaenoic acid (DHA) metabolism in vivo. Prostaglandins, Leukotrienes and Essential Fatty Acids (PLEFA), 88(1), 79-85. http://dx.doi.org/10.1016/j.plefa.2012.05.003

Rapoport, S. I., Ramadan, E., \& Basselin, M. (2011). Docosahexaenoic acid (DHA) incorporation into the brain from plasma, as an in vivo biomarker of brain DHA metabolism and neurotransmission. Prostaglandins \& other lipid mediators, 96(1), 109-113. http://dx.doi.org/10.1016/j.prostaglandins.2011.06.003

Rees, A. M., Austin, M. P., \& Parker, G. B. (2008). Omega-3 PUFAs as a treatment for perinatal depression: randomized double-blind placebo-controlled trial. Australian and New Zealand Journal of Psychiatry, 42(3), 199-205. http://dx.doi.org/10.1080/00048670701827267

Shapiro, G. D., Fraser, W. D., \& Séguin, J. R. (2012). Emerging risk factors for postpartum depression: serotonin transporter genotype and Omega-3 PUFAs status. Canadian journal of psychiatry. Revue canadienne de psychiatrie, 57(11), 704-712.

Stewart, D. E., Robertson, E., Dennis, C. L., Grace, S. L., \& Wallington, T. (2003). Postpartum depression: literature review of risk factors and interventions. Toronto: University Health Network Women's Health Program for Toronto Public Health.

Strøm, M., Mortensen, E. L., Halldorsson, T. I., Thorsdottir, I., \& Olsen, S. F. (2009). Fish and long-chain n- 3 polyunsaturated fatty acid intakes during pregnancy and risk of postpartum depression: a prospective study based on a large national birth cohort. The American journal of clinical nutrition, 90(1), 149-155. http://dx.doi.org/10.3945/ajen.2009.27552

Stuart, S., Couser, G., Schilder, K., O'HARA, M. W., \& Gorman, L. (1998). Postpartum anxiety and depression: onset and comorbidity in a community sample. The Journal of nervous and mental disease, 186(7), 420-424. http://dx.doi.org/10.1097/00005053-199807000-00006

Suarez, E. C., Krishnan, R. R., \& Lewis, J. G. (2003).The relation of severity of depressive symptoms to monocyte-associated proinflammatory cytokines and chemokines in apparently healthy men. Psychosomatic medicine, 65(3), 362-368. http://dx.doi.org/10.1097/01.PSY.0000035719.79068.2B

The Cochrane Collaboration. (2008). The Cochrane handbook for systematic reviews of interventions,

U. S. Food and Drug Administration/Center for Drug Evaluation and Research. (2014).

Van den Ham, E. C., van Houwelingen, A. C., \& Hornstra, G. (2001).Evaluation of the relation between $n-3$ and $\mathrm{n}-6$ fatty acid status and parity in nonpregnant women from the Netherlands. The American journal of clinical nutrition, 73(3), 622-627.

West Sussex, UK: John Wiley \& Sons.

World Health Organization. (2008). The Global Burden of Disease 2004 update. Retrieved from http://www.who.int/healthinfo/global_burden_disease/GBD_report_2004update_full.pdf 


\section{Appendix}

Appendix A: Tables

Table A1. Relevant Features of Included Studies

\begin{tabular}{|c|c|c|c|}
\hline Characteristics of the 17 Included Studies & Summary of Results & & \\
\hline Country & $\begin{array}{l}6 \text { USA } \\
3 \text { Australia } \\
3 \text { The Netherlands }\end{array}$ & $\begin{array}{l}1 \text { Norway } \\
1 \text { Denmark } \\
1 \text { Japan }\end{array}$ & $\begin{array}{l}1 \text { Brazil } \\
1 \text { New Zealand }\end{array}$ \\
\hline Design & $\begin{array}{l}6 \text { RCTs } \\
2 \text { Pilot trials }\end{array}$ & $\begin{array}{l}1 \text { Ecological } \\
1 \text { Cross-sectional }\end{array}$ & $\begin{array}{l}1 \text { Case-control } \\
6 \text { Cohort }\end{array}$ \\
\hline Sample Size & $\begin{array}{l}\text { Experimental 7-2399 } \\
\text { Observational 48-54202 }\end{array}$ & & \\
\hline Participants & 12 Healthy pregnant women & 3 Depressed women & 2 History of depression \\
\hline Objective & 3 Treatment & 5 Prevention & 9 Prevalence risk \\
\hline Intervention (clinical trials: $0.2-6 \mathrm{~g}$ ) & $\begin{array}{l}7 \mathrm{EPA}+\mathrm{DHA} \\
3 \text { Pure DHA } \\
1 \mathrm{DHA}+\mathrm{AA}\end{array}$ & $\begin{array}{l}1 \text { EPA, DHA, ALA } \\
3 \text { n-3/n-6 ratios }\end{array}$ & 2 total fatty acids \\
\hline Intervention Period (clinical trials) & $\begin{array}{l}6 \text { Perinatal } \\
2 \text { Postpartum }\end{array}$ & & \\
\hline Fatty Acids Measurement & $\begin{array}{l}4 \text { Blood test }+ \text { FFQ } \\
6 \text { only blood test }\end{array}$ & $\begin{array}{l}4 \text { only FFQ } \\
1 \text { Breast milk }\end{array}$ & 1 Cord blood \\
\hline Depression Measurement & $\begin{array}{l}7 \text { EPDS } \\
1 \text { HAM-D }\end{array}$ & $\begin{array}{l}2 \text { DSM } \\
4 \text { EPDS + HAM-D }\end{array}$ & $\begin{array}{l}2 \text { BDI } \\
1 \text { EPDS + DSM }\end{array}$ \\
\hline Quality Appraisal & 5 Strong & 9 Moderate & 3 Weak \\
\hline
\end{tabular}




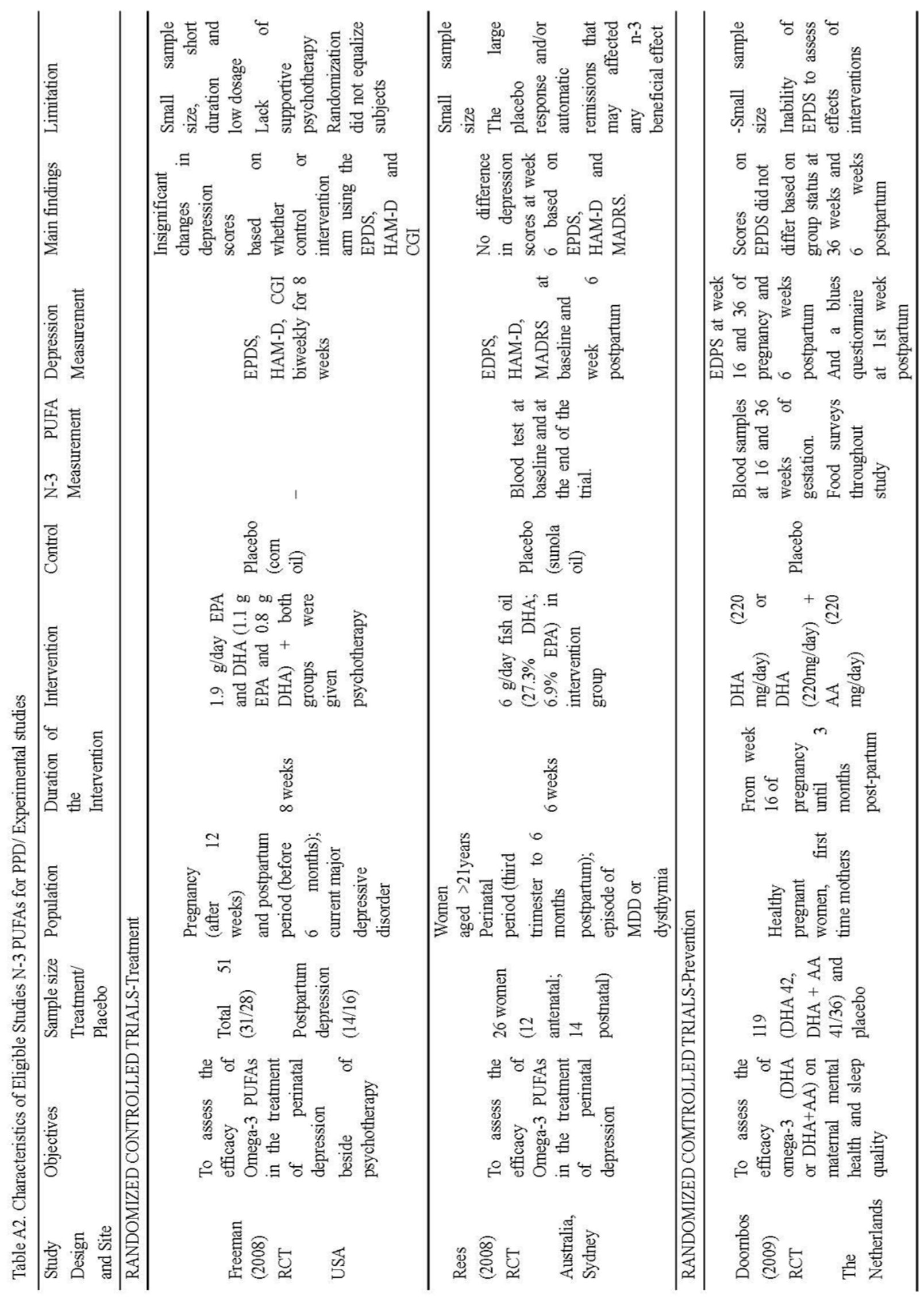




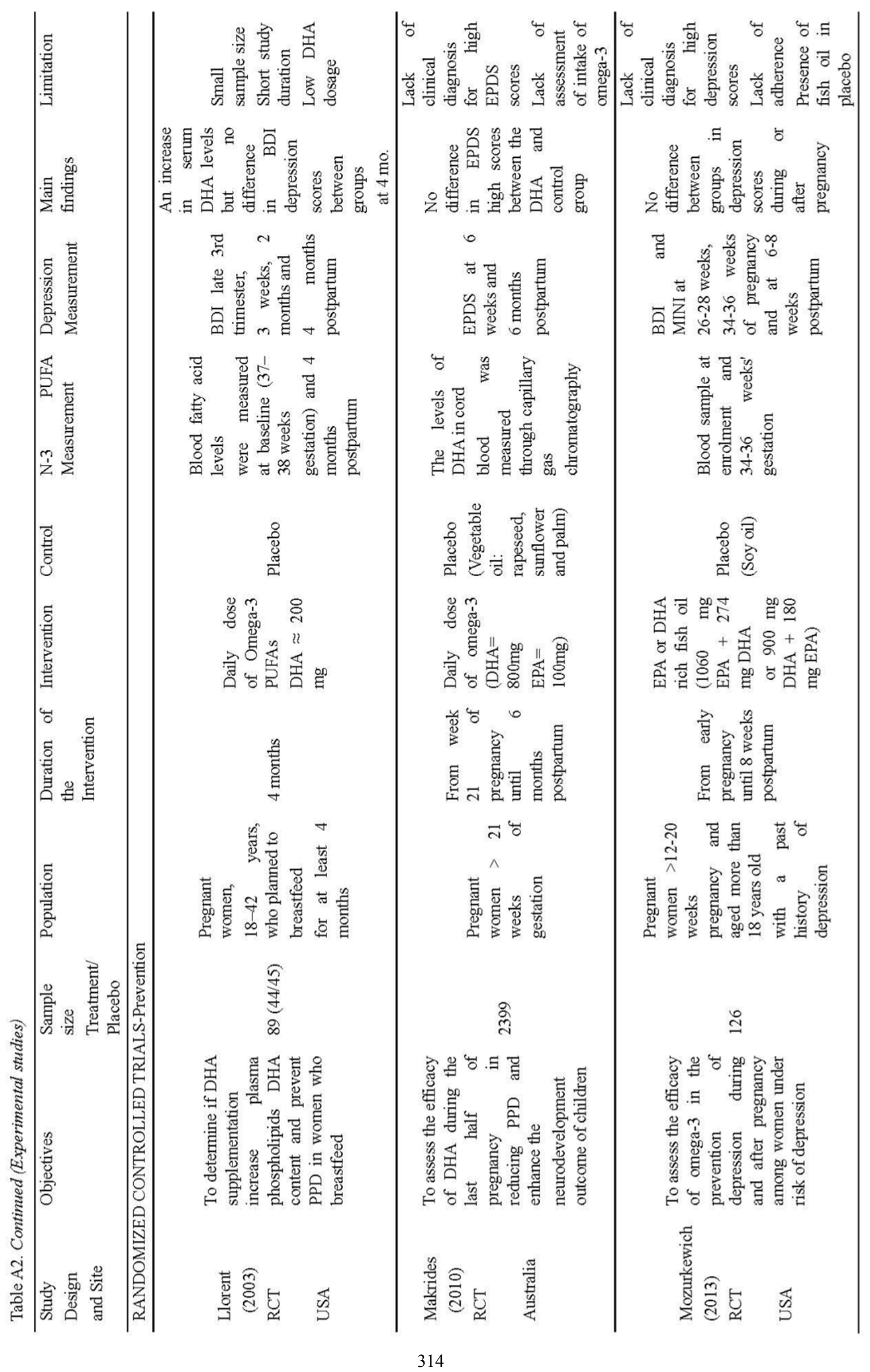




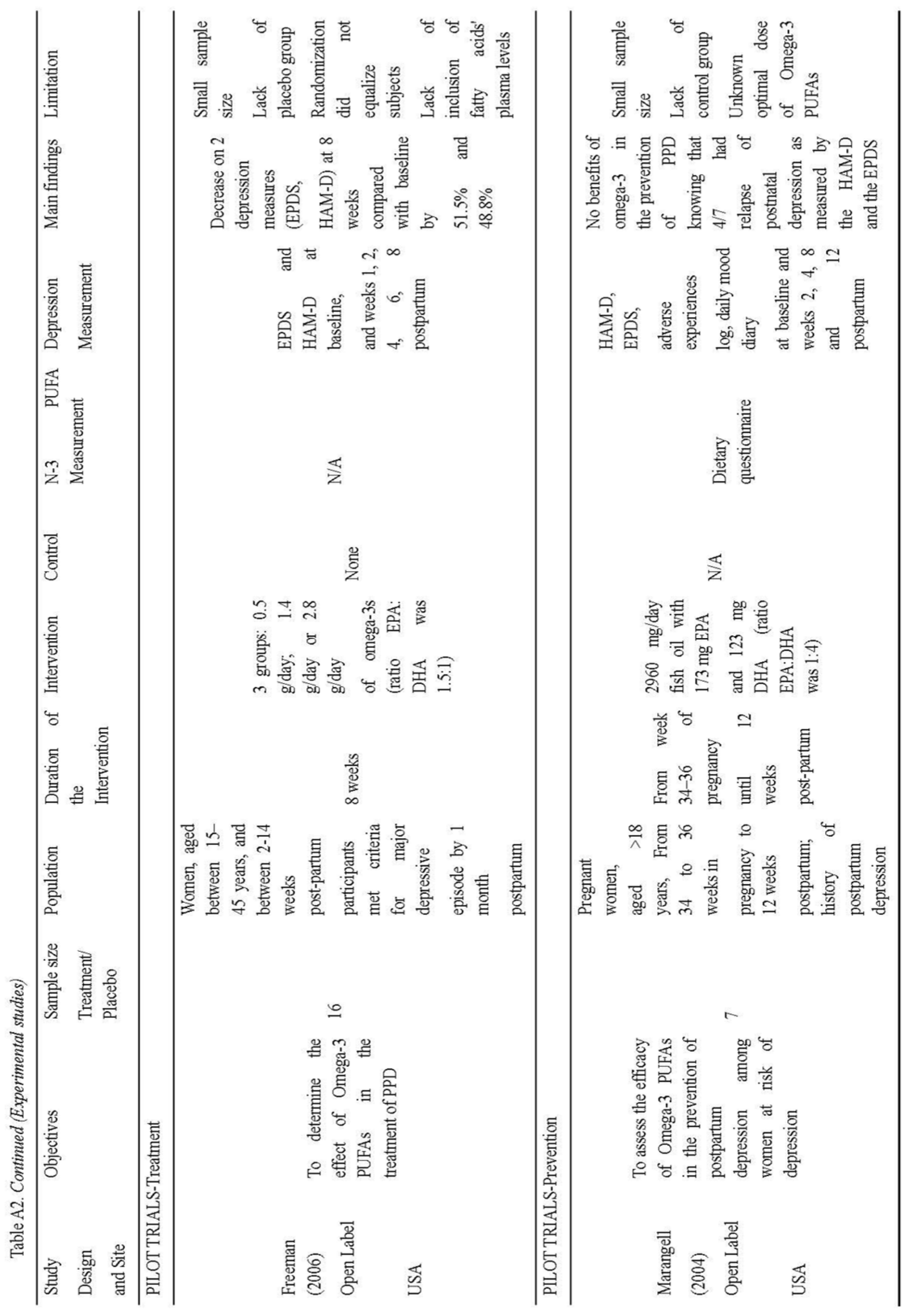




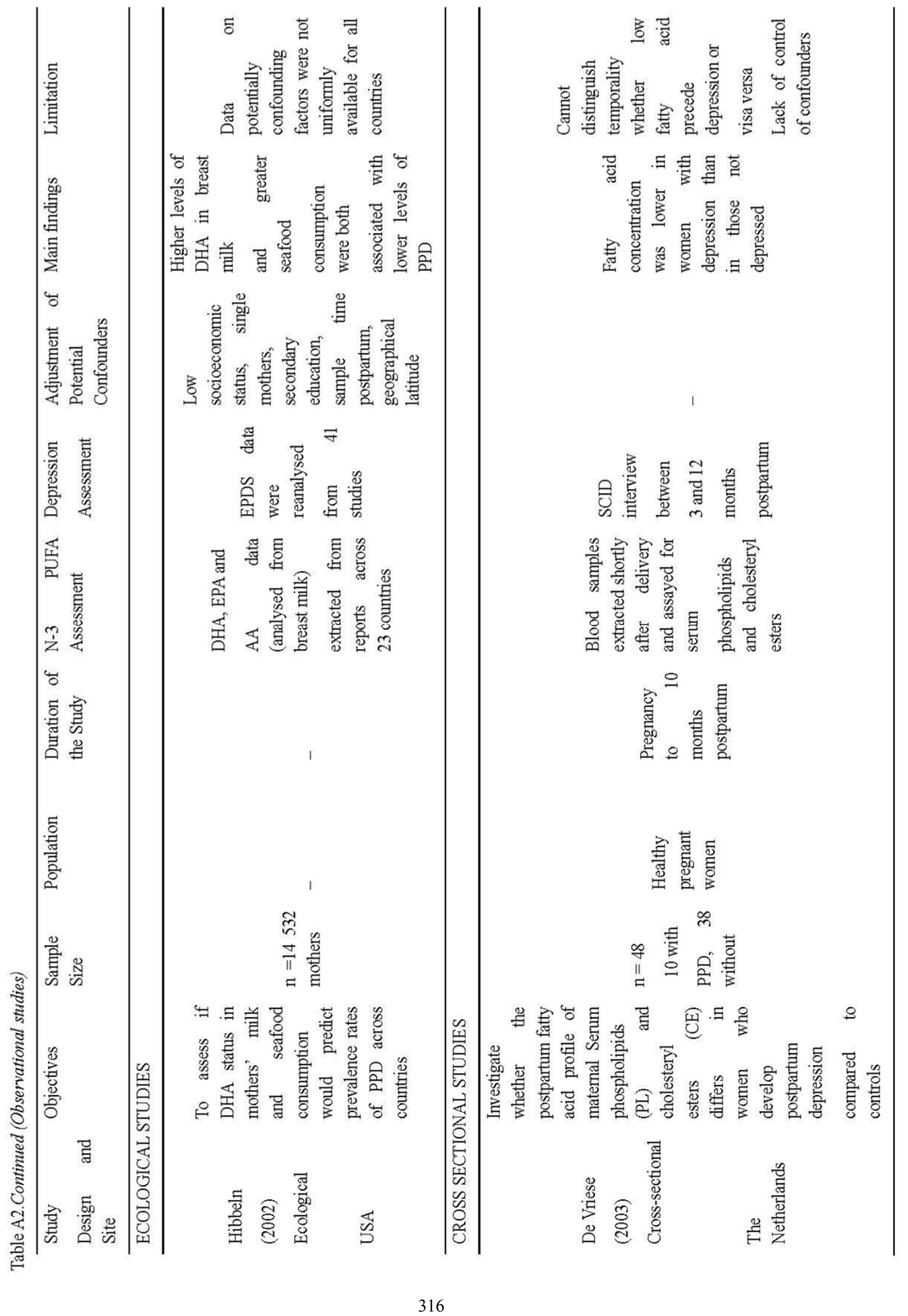




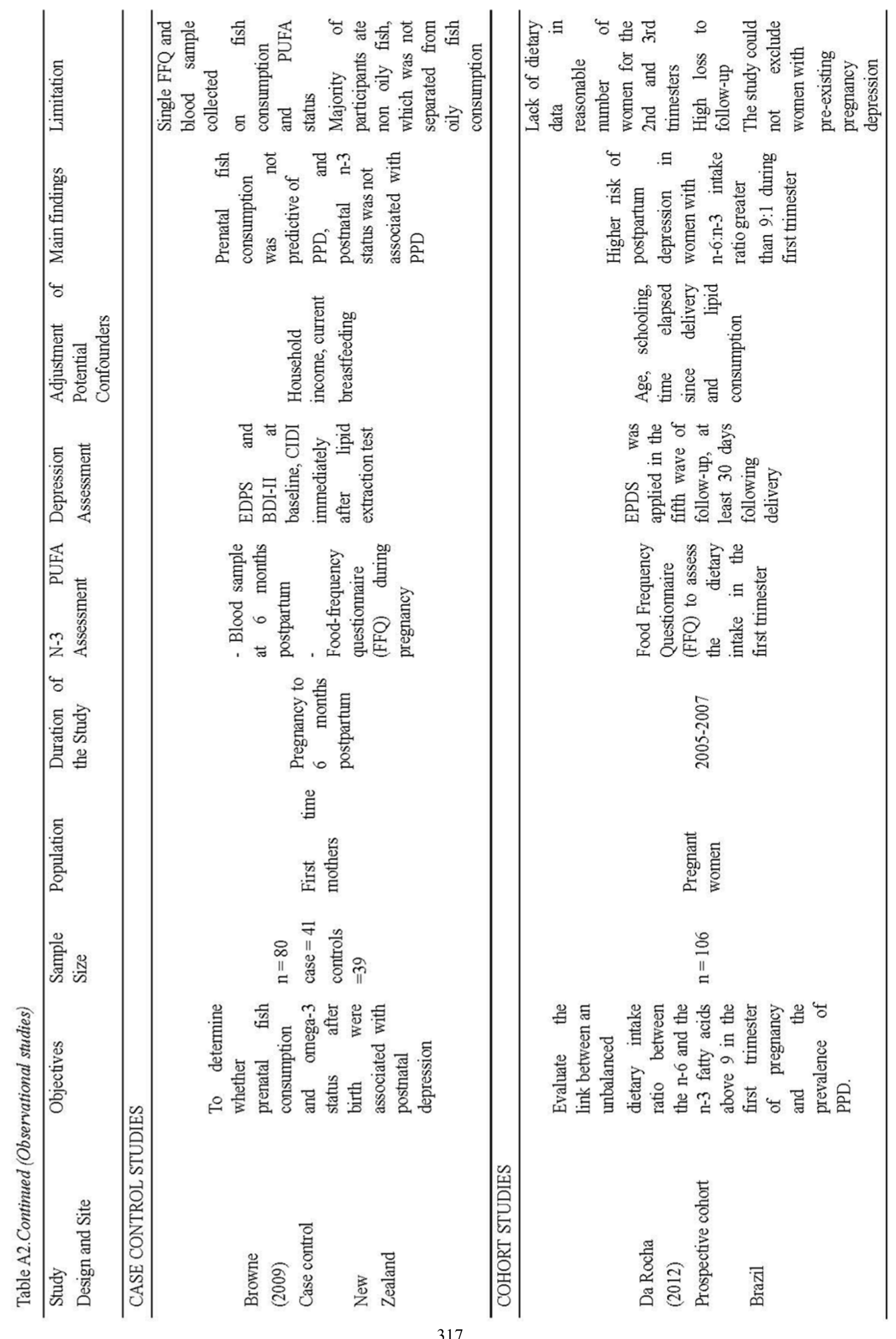




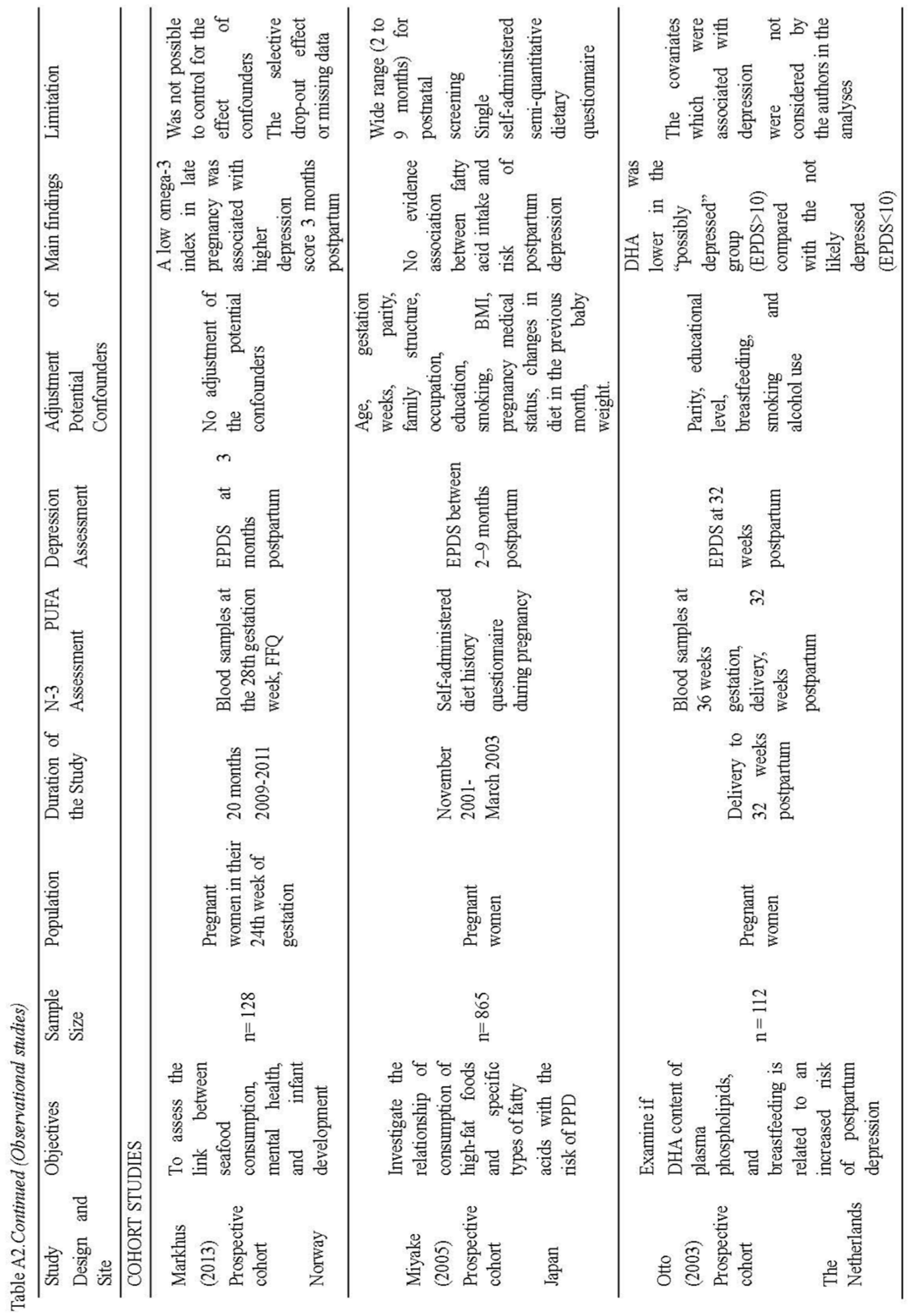




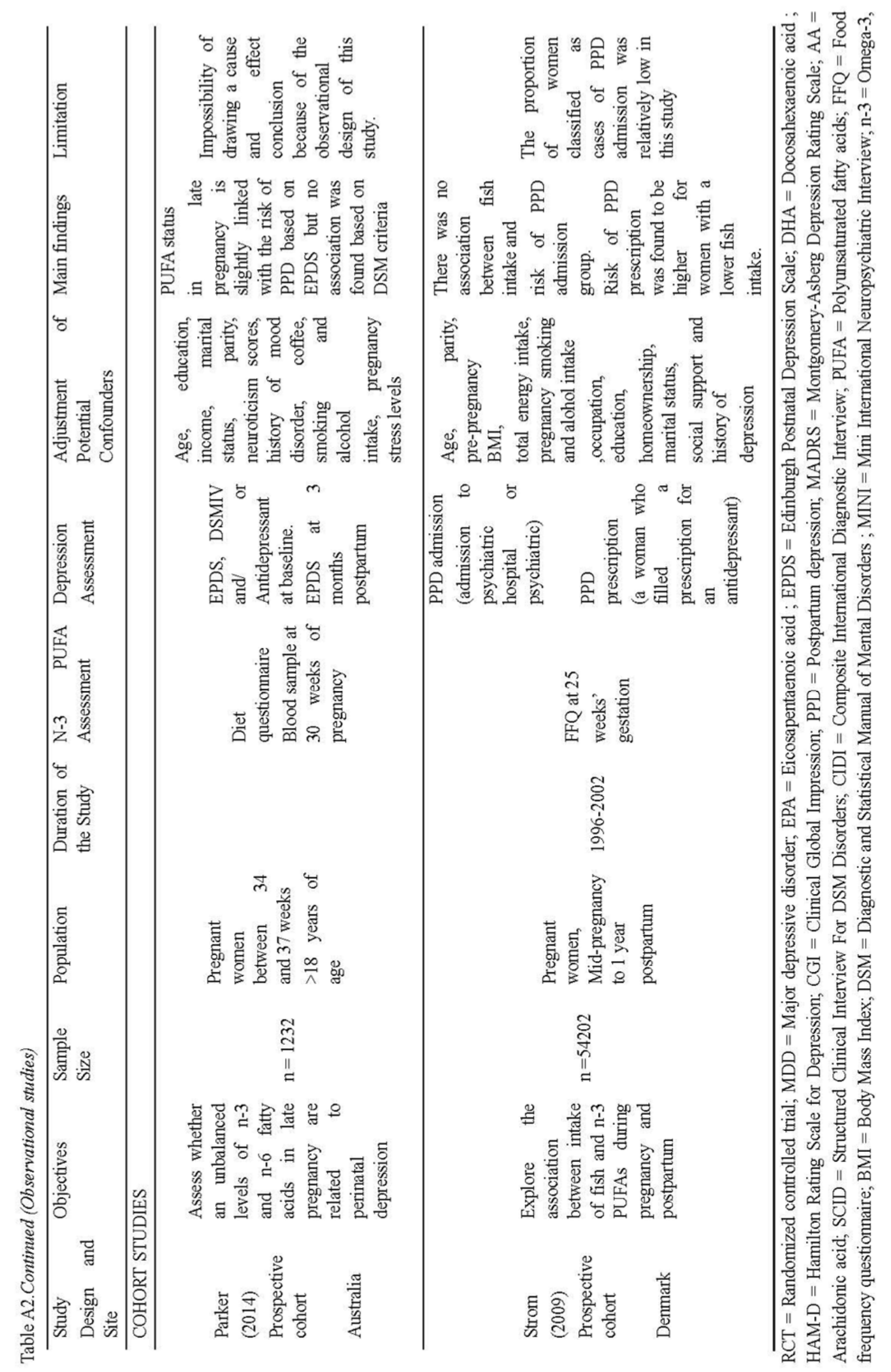

\section{Copyrights}

Copyright for this article is retained by the author(s), with first publication rights granted to the journal.

This is an open-access article distributed under the terms and conditions of the Creative Commons Attribution license (http://creativecommons.org/licenses/by/4.0/). 